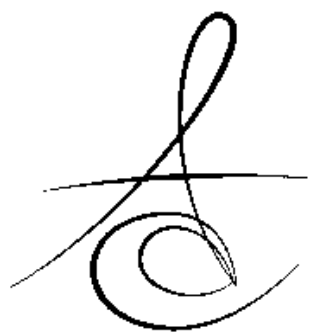

FOSFOR PLAK SİSTEMLERİNDE KARŞILAŞILAN TEMEL SORUNLAR

BASIC PROBLEMS IN PHOSPHOR STORAGE PLATE SYSTEMS

\author{
Öğr. Gör. Dr. Gökçen AKÇIÇEK* ${ }^{*}$ Doç Dr. Leyla Berna ÇAĞIRANKAYA* \\ Prof. Dr.Nihal AVCU*
}

Makale Kodu/Article code: 2345

Makale Gönderilme tarihi: 05.07.2015

Kabul Tarihi: 03.12.2015

öz

Gelişen teknoloji ile birlikte diş hekimliğinde konvansiyonel radyoloji dijital radyoloji ile yer değiştirmektedir. Charged-Coupled-Device, Complementary Metal Oxide Semiconducter ve fosfor plakları dijital radyolojide kullanılan sensörlerdir. Konvansiyonel filme olan benzerlikleri, kablosuz olmaları, mevcut film tutucular ile uyumlu olmaları ve diğer dijital sensörlere kıyasla daha ekonomik olmaları nedeniyle fosfor plak sistemleri dijital radyolojiye geçişte tercih edilen sensör olmaktadır. Ancak tüm sistemlerde olduğu gibi fosfor plak sistemlerinde de hata ve sorunların oluşması son derece doğaldır.

$\mathrm{Bu}$ çalışmada fosfor plak sistemlerinde karşılaşılan sorunlar; istenilen radyograf sayısı, koruyucu kılıflar, enfeksiyon kontrolü, plakların ters çekilmesi, çekimtarama süresi, tarama işlemi, plakların kullanım süresi ve görüntülerin yorumlanması başlıkları altında tartışımıştır. Amacımız fosfor plak sistemlerinde karşılaşılan sorunları, nedenlerini ve çözümlerini derleyerek kullanıcıların fosfor plak sistemlerini daha rahat ve bilinçli olarak kullanmalarına yardımcı olmaktır.

Anahtar kelimeler: Dijital radyoloji, Fosfor plak, Enfeksiyon kontrolü, Görüntü kalitesi

\section{Fosfor Plak Sistemlerinde Karşılaşılan Temel Sorunlar}

Dental radyoloji, diş hekimliğinin vazgeçilmez bir parçası olup X-ışınlarının keşfinden günümüze kadar geçen sürede gelişimini hızla sürdürmüştür. Günümüzde film bazlı konvansiyonel görüntüleme tekniklerinin yerini dijital sistemler almaktadır. Dijital radyolojik sistemler; direk (Charged-Coupled-Device (CCD), Complementary Metal Oxide Semiconducter(CMOS)) ve indirek (fosfor plakları (FP)) olarak sınıflandırılır.

\section{ABSTRACT}

Conventional film-based radiology used in dentistry has been replaced with digital radiology with the rapid advances in computer technology. Charged-CoupledDevice, Complementary Metal Oxide Semiconducter and storage phosphor plates are the sensors used in digital radiology. The phosphor storage plates are cordless and similar with conventional films, compatible with existing intraoral positioning devices and are low cost in comparison to the other digital sensors. Therefore, phosphor storage plates are the preferred sensors while transition to digital radiology. However, as like all systems it is very natural for problems and errors to occur in phosphor storage plate systems.

In this study the basic problems in phosphor storage plates are discussed under the topics of number of radiographs, protective barriers, infection control, reversed images, delay in processing time, processing procedure, utilization time and viewing conditions. Our aim was review the problems, their causes and solutions in phosphor storage plates and help the users to utilize this systems more comfortably and consciously.

Keywords: Digital radiology, Phosphor storage plates, Infection control, Image quality

FP'nın en büyük avantajı konvansiyonel filme benzer şekilde ince, esnek ve kablosuz olmalarıdır. ${ }^{1,2}$ Bu özelliklerinden dolayı hastalar açısından CCD sensörlere göre daha konforludurlar. ${ }^{3}$ Kullanım öncesinde hazırlık gerektirmesi, görüntünün plaklar tarandıktan sonra elde edilmesi ve tekrarlayan kullanımlar sonucunda görüntü kalitesinin azalması ise başlıca dezavantajlarıdır. ${ }^{1,4}$ FP sistemlerinin birbirleri ve diğer reseptörler ile karşılaştırıldığı birçok çalışmada farklı sonuçlara

\footnotetext{
* Hacettepe Üniversitesi, Diş Hekimliği Fakültesi, Ağız Diş Çene Radyolojisi AD.
} 
ulaşılmıs olmakla birlikte FP sistemlerinin görüntü kalitelerinin diğer reseptörlere benzer veya daha iyi olduğu bildirilmiştir. ${ }^{5-9} \mathrm{FP}$, dijital sisteme geçiş yapılacağı durumlarda, konvansiyonel filmle olan benzerlikleri ve CCD sensörlerine göre daha ucuz olması nedeniyle tercih edilebilir. ${ }^{4,10}$

Hekimlerin görüntüleme teknikleri konusundaki tercihleri incelendiğinde, dijital sistemler hakkında yeterli bilgiye sahip olmayan hekimlerin konvansiyonel teknikleri kullandıkları görülmektedir. ${ }^{11}$ Tüm yeni teknolojilere geçişte olduğu gibi konvansiyonel radyografiden FP sistemlerine geçişte farkllık ve sorunların ortaya çıkması kaçınılmazdır. Önemli olan bu sorunları ve nedenlerini saptayarak sistemin kullanışı bir hale getirilmesidir. Bu çalışmadaki amacımı FP sistemlerinde karşılaşılan sorunları, nedenlerini ve çözümlerini derleyerek kullanıcıların FP sistemlerini daha rahat ve bilinçli olarak kullanmalarına yardımcı olmaktır.

\section{İstenilen Radyograf SayIsı}

Dijital ve konvansiyonel sistem kullanan hekimlerin değerlendirildiği bir çalışmada, dijital reseptör kullanan hekimlerin daha fazla sayıda radyograf aldığı saptanmıştır. Bunun nedenleri arasında, dijital radyolojide radyasyon dozunun az olması, hatalar, görüntü kalitesi, ekstra kazanç ve hastaya sistemi tanıtmak gösterilmiştir. FP kullanan hekimlerin konvansiyonel film kullanan hekimlerden \%32 daha fazla radyograf aldığı, böylece dijital radyolojide azaldığı bilinen radyasyon dozunun klinik uygulamalarda düşünüldüğü kadar az olmadığı gösterilmiştir. ${ }^{12}$ Hekimler dijital radyoloji uygulamaları esnasında radyasyon dozunun az olması nedeni ile cömert davranmamalı, gerektiği kadar radyograf alarak radyasyondan korunma prensiplerine mutlaka uymalıdır.

\section{Koruyucu Killıf}

Plağı tükürük ve kan ile kontaminasyondan ve ışıktan korumak amacıyla kullanılan koruyucu kilfflar görüntü kalitesini etkileyebilir. Farklı koruyucu klıfların plakların görüntü kalitesi üzerindeki etkilerinin incelendiği bir çalışmada; orjinal siyah kılıflar ile elde edilen görüntülerin orjinal olmayan kllflar ile elde edilen görüntülerden daha iyi olduğu bulunmuştur. ${ }^{13}$

FP'larında karşılaşılan diğer bir sorun ise piyasada mevcut olan koruyucu kilıfların çoğunluğunun plaklardan daha geniş olmasıdır. Geniş kılıf kenarları çekim sırasında plak sınırlarının tam olarak görülmesini engellediğinden çekimde hatalara neden olabilmektedir. Bunu önlemek için plak kenarlarından taşmayan kılıfların kullanılması önerilmektedir. Kullanılan kılıfların siyah olması da plakların ağız içinde görülmesini güçleştiren diğer bir faktördür. ${ }^{10}$

\section{Enfeksiyon Kontrolü}

Radyoloji kliniklerindeki birçok farklı yüzeyde kontaminasyon riski olduğu bilinmektedir. ${ }^{14,15}$ Dijital sensörlerin konvansiyonel filmler gibi tek kullanımlık olmayıp yeniden kullanılması enfeksiyon kontrolü uygulamalarında farklııklara yol açmaktadır. Plaklar ağzı kapalı kılıflar içinde ağıza yerleştirilse de birçok kez yeniden kullanılmaları çapraz enfeksiyon riskine neden olmaktadır. Reseptörlerin kullanım öncesinde ve sonrasında uygun şekilde hazırlanması gerekmektedir. Yapılan çalışmalarda FP'lara uygulanan enfeksiyon kontrolü prosedürlerinin zor ve zaman alıı olduğu bildirilmiştir. ${ }^{16}$

Koruyucu kilıflar plağı, tükürük ve kan ile kontaminasyondan ve ışıktan korur. ${ }^{1,17}$ Ağıza yerleştirilmeden önce klıflarda herhangi bir hasar (yırtık, delik, kılıf ağzında yapıştıııının eksik veya hiç olmaması) olup olmadığı mutlaka kontrol edilmelidir. Kilıflarda fabrikasyon aşamasında veya plak yerleştirilirken uygulanan aşırı basınç nedeniyle oluşabilecek bu tarz defektler plakların kontamine olmasına neden olabilir. ${ }^{18}$ Bazı kılıfların yapışkan kenarları ağızda pozisyonlandırma sırasında uygulanan basınçla açılabilmekte ve bu da plağın kontamine olmasına neden olabilmektedir.

Kullanılmış olan kılıfı plaklar, çekim sonrasında tarayıcıya yerleştirilmeden önce yüzey dezenfektanı ile dezenfekte edilir. Ancak bu aşamada dikkat edilmesi gereken kılıf ıslakken açılmaya çalışıırsa plağın kontamine edilebileceğidir. Bu kontaminasyonu önlemek için dezenfektan uygulandiktan sonra mutlaka kurutulmaIıdır. Plak tekrar kullanılmadan önce alkol (\%70 etanol) veya klor bazlı bir dezenfektan ile temizlendikten sonra yeniden kılıfa yerleştirilip kullanıma sunulur. Plaklarda oluşan kolonilerin özellikle plakların kenarlarında yerleşim gösterdiği, plağın merkezinde ise çok az koloni saptandığı bildirilmiştir. Bu nedenle özellikle plak kenarlarının temizlik ve dezenfeksiyonuna dikkat edilmesi gerekmektedir. Bu işlemlere rağmen plaklarda bakteri ürediği bildirildiğinden, bu uygulamalara ilaveten plakların gün sonunda etilen oksit gazı ile sterilizasyona tabi tutulması önerilmektedir. ${ }^{16,19,20}$

Enfekte bir plağın taranması sonucunda tarayıcının ve dolayısıyla daha sonra taranacak olan diğer plakların da kontamine olabilme intimali vardır. 
Bazı firmaların tarayıcılarında bulunan otodezenfeksiyon sistemleri her tarama sonrasında veya gün sonunda cihaz kapanırken otomatik olarak devreye girip tarayıcıyı dezenfekte etmektedir. Wenzel ve ark ${ }^{21}$ yaptıkları bir çalışmada otodezenfeksiyon sisteminin mikroorganizmalar üzerinde etkili olduğunu saptamışlardır.

Dezenfektanların plaklarda hasara neden olabileceği de unutulmamalıdır. Etanol ve 2-propanolün Digora ve VistaScan FP'ları üzerindeki etkilerinin karşılaştırıldığı bir çalışmada VistaScan plaklarında etanol ile 5. silinmeden sonra, Digora plaklarında ise 60. silinmeden sonra defektler oluştuğu saptanmıştır. 2-propanolün ise mikroorganizmaları elimine etmede yetersiz olduğu, Digora plaklarında hasar oluşturmadığı, ancak VistaScan plaklarında 40. silinmeden sonra defektlere neden olduğu görülmüştür. ${ }^{21}$

\section{Plakların Ters Çekilmesi}

FP'larında karşılaşılan diğer bir sorun ise plakIarın ağız içine ters yerleştirilmesidir. Bu şekilde ekspoz edilen plaklarda görüntü ters taraf olarak yorumlandığından, tanı ve tedavide hatalara neden olabilmektedir. Günümüzde plakların ters yüzeyine metal şekiller konularak bu sorunun önüne geçilmeye çalışıımışır. Böylelikle plak ters yerleştirildiğinde elde edilen görüntüde bu şekil belirmekte ve hekimi uyarmaktadır (Şekil 1). Bazı sistemlerde ise ekspoz edilecek yüzeyde harfler yer almakta ve ters yerleştirilen plakta bu harfler ters olarak belirmektedir. Ters çekilmiş plaklar bilgisayar ortamında "ayna görüntüsü" fonksiyonundan yararlanılarak düzeltilebilir. ${ }^{4}$

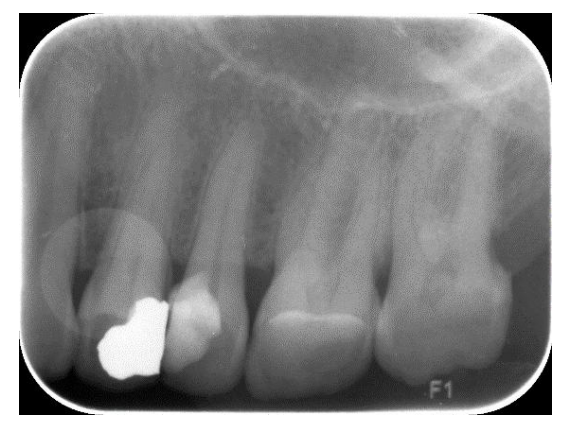

Şekil 1. Ters çekilmiş plak görüntüsü.

\section{Çekim-Tarama Süresi}

FP'nın görüntü kalitesini etkileyebilecek faktörlerin bilinmesi ve önlenmesi radyografik tanı için büyük önem taşımaktadır. FP'nın görüntü kalitsini etkileyen en önemli faktörler; taramaya kadar geçen süre ve plağın taramadan önce çevresel ışığa maruz kalmasıdır. ${ }^{1,17,22}$ Ekspoz-tarama arasındaki sürenin, görüntü kalitesi üzerindeki etkisini inceleyen çalışmalara bakıldığında farklı sonuçların elde edildiği görülmektedir. ${ }^{9,17,23-25}$ Akdeniz ve ark.larının ${ }^{17}$ çalışmasında plakların çekimi takiben 10 dakika içerisinde taranması gerektiği belirtilmiştir. Süre arttıkça özellikle koyu görüntü alanlarında görüntü kaybı olduğu ve bunun da kontrastta azalmaya neden olduğu bildirilmiştir. ${ }^{17}$ Aynı araştırmacıların bir yıl sonraki çalışmalarında ise bu sürenin 30 dakikaya kadar uzayabileceği ifade edilmiştir. ${ }^{24}$ Çalışmalar arasındaki bu farklılığa ekspoz parametrelerinin neden olabileceği; çok düşük doz radyasyon ile elde edilen görüntülerdeki kayıpların, yüksek doz ile elde edilenlere kıyasla daha fazla olabileceği belirtilmiştir. Bu nedenle çekimden sonra hemen taranamayacak plakların daha yüksek doz ile ekspoz edilmesi önerilmiştir. ${ }^{24}$ Martins ve ark. larının ${ }^{25}$ 2006 ylındaki makalelerinde plaklarda 4 saatte görüntü densitesinde kayıp olduğu, fakat bu kaybın klinik olarak fark edilebilecek düzeyde olmadığı rapor edilmiştir. İnsan gözünün en fazla 100 gri tonunu ayırt edebildiği, dolayısıyla oluşan densite kaybının insan gözünün algılayamadığı boyutlarda olduğu belirtilmiştir. ${ }^{25}$ Başka bir çalışmada ise plakların çekimden 120 dakika sonra taranması durumunda görüntü kalitesinde azalma olmakla birlikte bunun diagnostik açıdan sorun çıkarmayacak sınırlarda olduğu bildirilmiştir. ${ }^{23}$ Soğur ve ark.'larının ${ }^{22}$ çalışmalarında tarama süresinin 10 dakika gecikmesinin görüntü kalitesini olumsuz etkilediği ve 30 dakikalık gecikme sonucunda ise okluzal çürük tanısı doğruluğunun azaldığı tespit edilmiştir. Taramaya kadar geçen süre sonucunda meydana gelen görüntü kalitesindeki kayıpların sistemler arasında farklı olduğu, kimi sistemde 72 saate kadar görüntü kaybı olmazken bir diğerinde 6 saatte görüntü kalitesinde azalma olduğu bulunmuştur. ${ }^{9}$ Bununla birlikte yoğun çalışılan kliniklerde, tarama işleminin çekimden farklı bir birimde yapıldığı durumlarda, ekonomik sebepler nedeniyle birkaç kullanıcının tek bir tarayıı kullandığı yerlerde ve eğitim odaklı çalışan diş hekimliği ve röntgen teknisyenliği gibi okullarda çekilen plakların hemen taranaması mümkün olmayabilir.

Ekspoz edilmiş plakların saklama koşulları görüntü kalitesini etkileyen diğer bir unsurdur. Düşük ısıda bekletilen plaklardaki görüntü kaybının, normal oda ısısında bekletilenlerden daha fazla olduğu

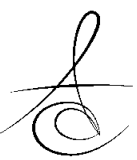


saptanmıştı. ${ }^{9}$ İki farklı FP sisteminin incelendiği başka bir çalışmada ise plakların taranmadan önce ışığa maruz kalması durumunda birinde 5 dakika, diğerinde ise 10 dakika sonrasında görüntü kalitesinde azalma olduğu bildirilmiştir. ${ }^{13}$

Tüm bu çalışmalar ışığında FP'nın çekimi takiben mümkün olan en kısa sürede taranması, taramanın hemen yapılamadığı durumlarda ise plakların oda sıcaklığında, ışık almayacak şekilde saklanması önerilebilir.

\section{Tarama İşlemi}

FP'lardaki latent imaj kırmııı ışı̆a $(600 \mathrm{~nm})$ çok duyarlı olduğundan konvansiyonel filmler için hazırlanmış karanlık odalar plakların tarama yapılması için uygun değildir. ${ }^{1} \mathrm{FP}$, görünür ışığa da duyarlı olduğundan tarama ortamı hafif ışıklandırımalı, plakların kılıttan çıkartııp taranması aşamasında hızlı davranılmalı ve böylece plakların çevresel ışı̆̆a maruziyetinin en aza indirilmesi sağlanmalıdır (Şekil 2). ${ }^{26,27}$ Özellikle çevresel ışı̆ıı fazla olduğu ortamlarda taşıyıciı sistemler yerine, plağın tarayıcıya doğrudan yerleştirildiği sistemler tercih edilmelidir. ${ }^{28}$

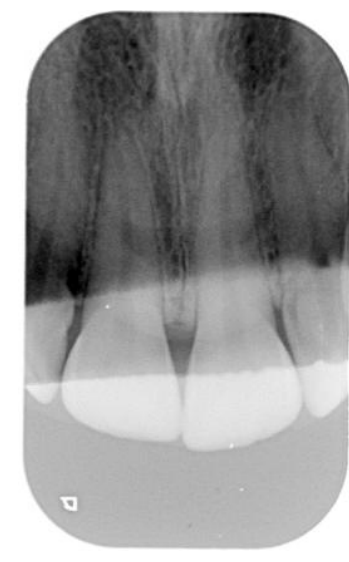

Şekil 2. Işık almış plak görüntüsü.

Eski FP sistemlerinde, plakların tarandıktan sonra üzerindeki görüntünün silinebilmesi için ışığa maruz bırakılması gerekmekteydi. Son dönemlerde üretilen sistemlerde ise plaklar taranırken silinebilmektedir. Silme işlemini tarayııının yapmadığı sistemlerde, ekspoz olmuş bir plağın normal oda ışığına birkaç saniye maruz kalması görüntünün büyük bir kısmında kayba neden olsa da tamamının silinmesi için plağın parlak ışıkta daha uzun süre bekletilmesi gerekir. ${ }^{26}$ Silme süresinin değerlendirildiği farklı çalışmalar olmakla birlikte Melo ve ark. ${ }^{29}$ plakların en az 25 saniye süreyle 1700 lux ışığa maruz bırakılması gerektiğini bildirmişlerdir. Bu sürenin altındaki uygulamalarda görüntünün kontrast, parlaklık, keskinliğinin azaldığı, mine, dentin ve mine-dentin sınırının net izlenemediği ve görüntüde "çift görüntü" oluştuğu rapor edilmiştir. ${ }^{29}$

Tarayıcıya bağlı olarak, görüntüde fazladan horizontal beyaz çizgi oluşması, tarama parametrelerinin optimal olmasına karşlık görüntünün çok parlak olması (Şekil 3), ekranda görüntünün sadece bir kısmının oluşması, görüntü boyutunun küçülmesi, farklı iki görüntünün süperpoze olması (Şekil 4) gibi artefaktlar oluşabilir. Bu gibi durumlarda plaklar taranırken silinmemişse aynı plak yeniden tarandığında görüntünün düzgün bir şekilde elde edildiği bildirilmiştir. ${ }^{4}$ Birçok sistemde tarama sırasındaki silme fonksiyonu kaldırıabilmektedir. Bu sayede tarayıcı kaynaklı tekrarların önüne geçilebilir, fakat silme işlemi için ekstra süreye intiyaç duyulur. ${ }^{4}$

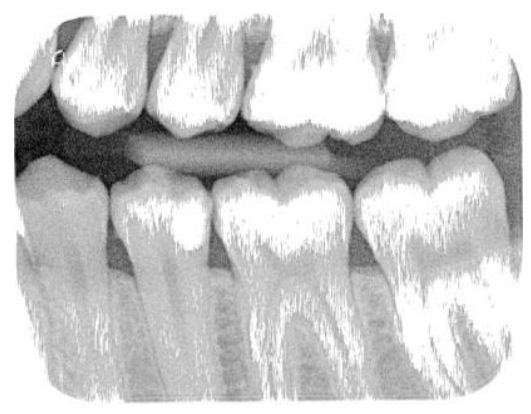

Şekil 3. Optimal tarama parametrelerine rağmen parlak görüntü oluşumu.

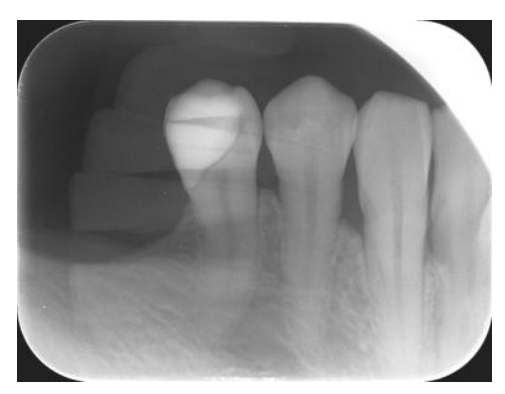

Şekil 4. İki farklı görüntünün süperpoze olması.

\section{Plakların Kullanım Süresi (Plaklarda Oluşan Çizikler)}

Günümüzde FP kullanımı sırasında en sık karşılaşılan sorunlardan biri de plaklarda mekanik hasara bağlı olarak oluşan çiziklerdir. Bu çizikler görüntünün diagnostik kalitesini azaltarak plağın kullanım süresini olumsuz yönde etkilemektedir (Şekil 5). Plaklar tarama

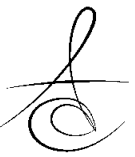


sırasında özellikle de plak yönlendirici tarayıcılarda, hasta tarafından ısırılma sonucunda (Şekil 6) ve sert yüzeylere düşürülmeleri sonucunda çizilebilir. 4,30,31 Tekrarlayan kullanımlar sonucunda plakları kaplayan fosfor halit emülsüyonunda kısmi soyulmalar olduğu da rapor edilmiştir. ${ }^{4}$ Bu tarz mekanik hasarları önlemek için ekspoz edilmiş plaklar kllıttan sünger üzerine düşürülebilir ve plakların toplandığı ve temizlenip yeniden kılıflandığı alanlar plastik örtülerle kaplanabilir. ${ }^{10}$

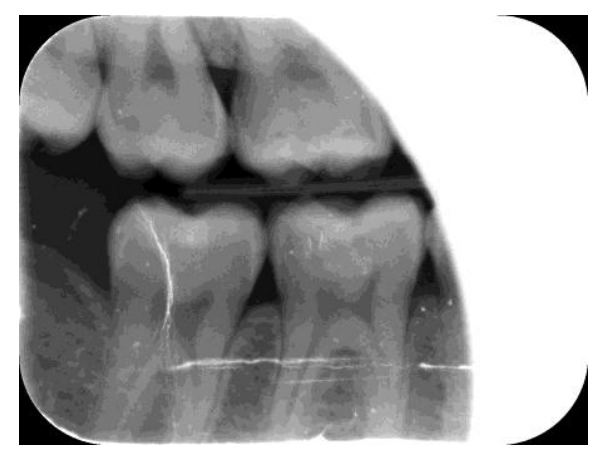

Şekil 5. Tekrarlayan kullanımlar sonucunda plaklarda oluşan çizikler.

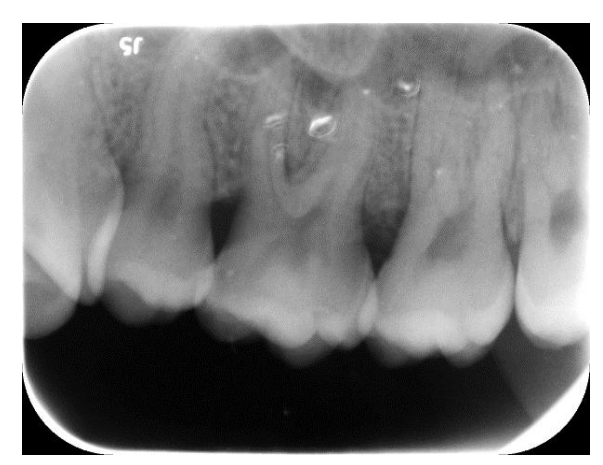

Şekil 6. Plaklarda ısırımaya bağlı olarak oluşan hasarlar

FP'nın kullanım süreleri araştııılığında literatürde birçok farklı sonuca ulaşılmaktadır. Bedard ve ark. $^{31}$ diş hekimliği öğrencilerinin kullandıkları plakları incelemişlerdir. Çalışmalarının sonucunda plakların 30 kullanım sonunda yaklaşık yarısında ciddi çizikler oluştuğunu ve 50 kullanım sonunda ise bu oranın \%95'e çıktığını bildirmişlerdir. Bu bilgiler doğrultusunda FP'nın 50 kez kullanıldıktan sonra değiştirilmesi gerektiğini önermişlerdir. ${ }^{31} \mathrm{Bu}$ çalışmanın tecrübesi sınırlı olan diş hekimliği öğrencileri ile gerçekleştirilmiş olduğuna dikkat edilmelidir. Daha tecrübeli hekim ve/veya teknisyenlerin çalıştı̆ı kliniklerde bu rakamın daha üst sınırlara çıkabileceği göz önünde bulundurulmalıdır. Örneğin Ergün ve ark.nın ${ }^{28}$ çalışmalarında plakların 200 kullanım sonrasında hala kullanılabilir halde olduğu tespit edilmiştir.

\section{Görüntülerin Yorumlanması}

Tüm diagnostik görüntüler ister konvansiyonel ister dijital olsun, loş (çevresel ışığın az olduğu) ortamda değerlendirilmelidir. ${ }^{32}$ Özellikle konvansiyonel filmden dijitale geçen hekimlerde dijital görüntülerin ekran üzerinden yorumlanması güçlük yaratmaktadır. ${ }^{12}$

\section{SONUÇ}

1. Hekimler, dijital radyoloji uygulamaları esnasında radyasyon dozunun az olması nedeni ile cömert davranmamalı, gerektiği kadar radyograf alarak radyasyondan korunma prensiplerine mutlaka uymalı,

2. Orjinal ve plak kenarlarından taşmayan kllflar tercih edilmeli,

3. Kullanım öncesinde koruyucu kilıflarda herhangi bir hasar olup olmadığı kontrol edilmeli, taramadan önce kllıf üzerine uygulanan dezenfektan kuruduktan sonra klıf açılmalı, plaklar her hasta arasında dezenfektan ile silinmeli, gün sonunda gaz sterilizasyonuna tabi tutulmall, mümkünse otodezenfeksiyon programı olan tarayıcilar kullanılmalı,

4. FP ekspoz edildikten sonra en kısa sürede taranmalı, tarama çevresel ışı̆ın az olduğu bir ortamda yapilmalı,

5. Plaklar kıvrılmamalı, sert yüzeylere temas ettirilmemeli, hasarlı plaklar saptanarak kullanımdan çıkartılmalı,

6. Görüntüler loş ortamda yorumlanmalıdır.

\section{KAYNAKLAR}

1. White SC, Pharoah MJ. Oral Radiology Principles and Interpretation. 5 ed. St. Louis (MO); Mosby: 2004. p. 225-44.

2. Soğur E, Baskı BG. İntraoral görüntüleme sistemleri. Atatürk Üniv Diş Hek Fak Derg 2011;21:249-54.

3. Gonçalves A, Wiezel VG, Gonçalves M, Hebling J, Sannomiya EK. Patient comfort in periapical examination using digital receptors. Dentomaxillofac Radiol 2009;38:484-8. 
4. Chiu HL, Lin $\mathrm{SH}$, Chen $\mathrm{CH}$, Wang $\mathrm{WC}$, Chen JY, Chen YK, Lin LM. Analysis of photostimulable phosphor plate image artifacts in an oral and maxillofacial radiology department. Oral Surg Oral Med Oral Pathol Oral Radiol Endod 2008;106:74956.

5. Farrier $S L$, Drage NA, Newcombe RG, Hayes $S$, Dummer PMH. A comparative study of image quality and radiation exposure for dental radiographs produced using a charge-coupled device and a phosphor plate system. Int Endod J 2009;42:900-7.

6. Jorgenson T, Masood F, Beckerley JM, Burgin C, Parker DE. Comparison of two imaging modalities: F-speed film and digital images for detection of osseous defects in patients with interdental vertical bone defects. Dentomaxillofac Radiol 2007;36:5005.

7. Kitagawa $H$, Farman AG, Scheetz JP, Brown WP, Lewis J, Benefiel M, Kuroyanagi K. Comparison of three intra-oral storage phosphor systems using subjective image quality. Dentomaxillofac Radiol 2000;29:272-6.

8. Syriopoulos K, Sanderink GCH, Velders XL, van der Stelt PF. Radiographic detection of approximal caries: a comparison of dental films and digital imaging systems. Dentomaxillofac Radiol 2000;29:312-8.

9. Martins MGBQ, Haiter Neto F, Whaites EJ. Analysis of digital images acquired using different phosphor storage phosphor plates (PSPs) subjected to varying reading times and storage conditions. Dentomaxillofac Radiol 2003;32:186-90.

10. Tax CL, Robb CL, Brillant MGS, Doucette HJ. Integrating photo-stimulable phosphor plates into dental and dental hygiene radiography curricula. J Dent Edu 2013;77:1451-60.

11. Soğur $E$, Akdeniz BG. Dişhekimleri ve dişhekimliği öğrencilerinin dijital radyografi hakkındaki bilgi, tutum ve davranışlarının değerlendirilmesi. AÜ Diş Hek Fak Derg 2005;32:207-13.

12. Berkhout WER, Sanderink GCH, Van der Stelt PF. Does digital radiography increase the number of intraoral radiographs? A questionnaire study of Dutch dental practices. Dentomaxillofac Radiol 2003;32:124-7.
13. Aktan AM, Çitçi ME, Akgünlü F. Comparison of the delay in processing time and protective plastic cases in two phosphor plate systems. Scientific World Journal 2012;2012:850764. Doi: 10.1100/2012/850764.

14. Freitas CVS, Dias LS, Araujo CS, Da Silva VC, Monteiro-Neto V, Souza JIL. Assessment of microbiological contamination of radiographic devices in school of dentistry. Braz Dent Sci 2012;15:39-46.

15. Fernandes LMPSR, Zapata RO, Rubira-Bullen IRA, Capelozza ALA. Rev Gaucha Odontol, Porto Alegre 2013;61:609-14.

16. Negron W, Mauriello SM, Peterson CA, Arnold R. Cross-contamination of the PSP sensor in a preclinical setting. J Dent Hyg 2005;79:1-10.

17. Akdeniz BG, Gröndahl HG, Kose T. Effect of delayed scanning of storage phosphor plates. Oral Surg Oral Med Oral Pathol Oral Radiol Endod 2005;99:603-7.

18. MacDonald DS, Waterfield JD. Infection control in digital intraoral radiography: evaluation of microbiological contamination of photostimulable phosphor plates in barrier envelopes. J Can Dent Assoc 2011;77:b93.

19. Kalathingal SM, Moore S, Kwon S, Schuster GS, Shrout MK, Plummer K. An evaluation of microbiologic contamination on phosphor plates in a dental school. Oral Surg Oral Med Oral Pathol Oral Radiol Endod 2009;107:279-82.

20. Kalathingal S, Youngreter A, Minton J, Shrout MK, Dickinson D, Plummer K, Looney S. An evaluation of microbiologic contamination on a phosphor plate system: is weekly gas sterilization enough? Oral Surg Oral Med Oral Pathol Oral Radiol Endod 2010;109:457-62.

21. Wenzel A, Kornum F, Knudsen MR, Lau EF. Antimicrobial efficiency of ethanol and 2-propanol alcohols used on contaminated storage phosphor plates and impact on durability of the plate. Dentomaxillofac Radiol 2013;42:20120353. Doi: 10.1259/dmfr.2012353.

22. Soğur E, Baksı BG, Mert A. The effect of delayed scanning of storage phosphor plates on occlusal caries detection. Dentomaxillofac Radiol 2012;41:309-15. 
23. Bramante CM, Bramante AS, Souza RE, Moraes IG, Bernardineli N, Garcia RB. Evaluation of the effects of processing delays and protective plastic ceses on image quality of a photostimulable phosphor plate system. J Appl Oral Sci 2008;16:350-4.

24. Akdeniz BG, Gröndahl HG. Degradation of storage phosphor images due to scanning delay. Dentomaxillofac Radiol 2006;35:74-7.

25. Martins MGBQ, Whaites EJ, Ambrosano GMB, Haiter Neto F. What happens if you delay scanning Digora phosphor storage plates (PSPs) for up to 4 hours? Dentomaxillofac Radiol 2006;35:143-6.

26. Molteni R. Effect of visible light on photostimulated-phosphor imaging plates. International Congress Series 2003;1256:1199-205.

27. Ramamurthy R, Canning CF, Scheetz JP, Farman AG. Impact of ambient lighting intensity and duration on the signal-to-noise ratio of images from photostimulable phosphor plates processed using DenOpti ${ }^{\circledR}$ and $\operatorname{Scan} X^{\circledR}$ systems. Dentomaxillofac Radiol 2004;33:307-11.

28. Ergün $S$, Güneri $P$, İlgüy $D$, İlgüy $M$, Boyacıoğlu $H$. How many times can we use a phosphor plate? A priminary study. Dentomaxillofac Radiol 2009;38:42-7.

29. Melo DP, dos Anjos Pontual A, de Almeida SM, Campos PSF, Alves MC, Tosoni GM. Effect of alternative photostimulable phosphor plates erasing times on subjective digital image quality. Dentomaxillofac Radiol 2010;39:23-7.

30. Ramamurthy R, Canning CF, Scheetz JP, Farman AG. Time and motion study: a comparison of two photostimulable phosphor imaging systems used in dentistry. Dentomaxillofac Radiol 2006;35:315-8.

31. Bedard A, Davis TD, Angelopuolos C. Storage phosphor plates: how durable are they as a digital dental radiographic system? J Contemp Dent Pract 2004;15:57-69.

32. Farman AG, Farman TT. A comparison of 18 different X-ray detectors currently used in dentistry. Oral Surg Oral Med Oral Pathol Oral Radiol Endod 2005;99:485-9.

\section{Yazışma Adresi}

Öğr.Gör. Dr. Gökçen AKÇIÇEK

Hacettepe Üniversitesi

Diş Hekimliği Fakültesi

Ağız, Diş ve Çene Radyolojisi AD.

e-mail: gokcen.akcicek@hacettepe.edu.tr 